\title{
Synthesis of Isocoumarins
}

\section{Part I. $( \pm)$-Mellein}

\author{
By Masanao Matsui, Kenji Mori and Seitetsu Arasaki
}

Department of Agricultural Chemistry, Faculty of Agriculture, The University of Tokyo, Tokyo

Received July 27, 1964

(士)-Mellein (ochracin) was synthesized from 4-bromo-7-methoxy-indanone via 3-methyl8-hydroxyisocoumarin.

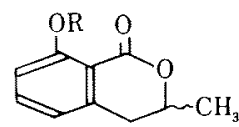

I $\mathrm{R}=\mathrm{H}$

II $\mathrm{R}=\mathrm{CH}_{3}$<smiles>[R20]c1cccc2cc(C)oc(=O)c12</smiles>

III $\mathrm{R}=\mathrm{H}$

XI $\mathrm{R}=\mathrm{CH}_{3}$<smiles>COc1ccc(Br)c2c1CCC(=O)OCC(=O)Cc1c(Br)cc(Br)c(c1OC)C2</smiles>

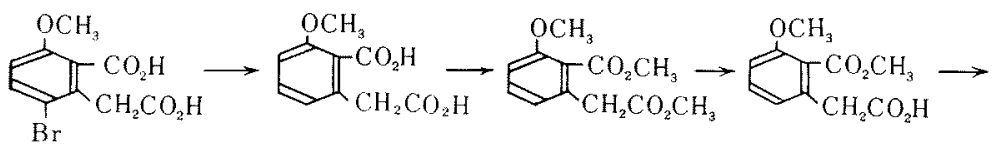

VI

VII

VIII

$[X$<smiles>[X]c1cccc(OC)c1C(=O)CC(=O)Cl</smiles><smiles>COc1ccc(CC(=O)O)c(C(=O)O)c1C</smiles>
$\mathrm{CH}_{2} \mathrm{COCH}\left(\mathrm{CO}_{2} \mathrm{C}_{2} \mathrm{H}_{5}\right)_{2}$<smiles>COc1cccc2cc(C)oc(=O)c12</smiles>

XI<smiles>CC1Cc2ccc(I)c(O)c2C(=O)O1</smiles>

I
XII<smiles>COc1cccc2c1C(=O)OC(=CC=O)C2</smiles>

XII

Mellein ( $\mathrm{I}, \quad(-)$-3-methyl-8-hydroxy-3,4-di- ochraceus isolated by them. ${ }^{3,4}$ )

hydroisocoumarin) was first discovered by Nishikawa in 1933 as a metabolite of Aspergillus melleus.1.2) In the same year, Yabuta and Sumiki established the identity of mellein with ochracin, a metabolite of Aspergillus

1) H. Nishikawa, J. Agr. Chem. Soc. Japan, 9, 772 (1933).

2) H. Nishikawa, ibid., 9, 1059 (1933).
Although ( \pm ) -mellein methyl ether (II) has been synthesized by Blair and Newbold, ${ }^{5,6)}$ no direct synthesis of $( \pm)$-mellein has been accomplished.

3) T. Yabuta and Y. Sumiki, J. Agr. Chem. Soc. Japan, 9, 4) 1264 (1933).

and Y. Sumiki, ibid., 10 703 (1954).

5) J. Blair and G. T. Newbold, Chem. \& Ind., 1955, 93. 
This paper describes a synthesis of $( \pm)$ mellein via 3-methyl-8-hydroxyisocoumarin (III) which itself has been obtained as a metabolite of Marasmius ramealis and correlated with $( \pm)$-mellein (I).7,8)

4-Bromo-7-methoxyindanone (IV) ${ }^{9}$ was nitrosated to give an $\alpha$-oximinoketone (V), m.p. $233 \sim 236^{\circ} \mathrm{C}$. The Beckmann rearrangement followed by alkaline hydrolysis of the oximinoketone (V) yielded 2-carboxy-3-methoxy6-bromophenylacetic acid (VI), m.p. 183.5 $184.5^{\circ} \mathrm{C}$, which was debrominated by catalytic hydrogenation to give 2-carboxy-3-methoxyphenylacetic acid (VII), m.p. $165 \sim 166^{\circ} \mathrm{C}$. The corresponding dimethyl ester (VIII) was partially saponified to give 2-carbomethoxy-3methoxyphenylacetic acid (IX), m.p. 106 $107^{\circ} \mathrm{C}$. This half ester was converted into the corresponding acyl chloride (X). Condensation of the acyl chloride (X) with diethyl ethoxymagnesiomalonate followed by acid hydrolysis, decarboxylation and cyclization gave crude 3-methyl-8-methoxyisocoumarin (XI) as an oil. Treatment of the crude oil (XI) by refluxing with hydriodic acid gave needles of 3-methyl-8-hydroxyisocoumarin (III), m.p. $101 \sim 102^{\circ} \mathrm{C}$. Comparison of the infrared and ultraviolet data of the synthetic material with the published data ${ }^{7)}$ proved the identity of our sample with the metabolite. The over-all yield of the isocoumarin (III) from the indanone (IV) was $14 \%$.

An alternate route to the isocoumarin (III) was also investigated. The following procedure may serve as a new general route to 3-methyl-8-methoxyisocoumarins. The homophthalic acid (VII) was refluxed with acetic anhydride in the presence of sodium acetate. The reaction mixture was then diluted with

7) G. Benz, Arkiv. Kemi, 14, 511 (1959).

8) G. Bendz, ibid, 15, 131 (1960).

9) R. A. Barnes, E. R. Kraft and L. Gordon, J. Am. Chem. Soc., 71, 3523 (1949). water while warm. The obtained crystalline product, m.p. $109.5 \sim 110.5^{\circ} \mathrm{C}$, was assumed to be 3-methyl-8-methoxyisocoumarin (XI) by considering both analytical and spectral data. Refluxing of this substance with hydriodic acid gave 3-methyl-8-hydroxyisocoumarin (III) identified with an authentic sample by mixed melting point and infrared spectrum. This proved the assigned structure (XI) for the substance melting at $109.5 \sim 110.5^{\circ} \mathrm{C}$. Direct formation of the isocoumarin ring from the homophthalic acid (VII) was thus accomplished. The possible intermediate in this one-step synthesis of the isocoumarin is either XII or XIII. ${ }^{10)}$ However, no further mechanistic study was attempted.

Conversion of 3-methyl-8-hydroxyisocoumarin (III) to ( \pm ) -mellein (I) was carried out as described by Bendz. ${ }^{7}$ The infrared spectrum of the solution of the synthetic material (I) , m.p. $37 \sim 38^{\circ} \mathrm{C}$, was identical with that of the natural product kindly given us by Dr. N. Takahashi from the collection of Professors T. Yabuta and Y. Sumiki.

\section{EXPERIMENTAI}

All melting points are uncorrected. Infrared spectra refer to Nujol mulls for solid samples and liquid films for liquid samples.

2-0ximino-4-bromo-7-methoxyindanone (V). To a solution of 4-bromo-7-methoxyindanone (IV, 45.8g) and isoamyl nitrite $(69 \mathrm{ml})$ in $99 \%$ ethanol $(600 \mathrm{ml})$ was gradually added concd. hydrochloric acid $(8.7 \mathrm{ml})$. The reaction mixture was kept at $45 \sim 50^{\circ} \mathrm{C}$ for $40 \mathrm{~min}$. The precipitated crystals were collected and recrystallized from ethanol. Yield, $45 \mathrm{~g}(87 \%)$. Pale yellow needles, m.p. $233 \sim 236^{\circ} \mathrm{C}$ (dec.). Anal. Found: C, 44.72 : $\mathrm{H}, 3.13 ; \mathrm{N}, 5.16$. Calcd. for $\mathrm{C}_{10} \mathrm{H}_{8} \mathrm{O}_{3} \mathrm{NBr}: \mathrm{C}, 44.47 ; \mathrm{H}$, $2.98 ; \mathrm{N}, 5.19 \% . \quad \nu_{\max } 3260,1697,1630,1585 \mathrm{~cm}^{-1}$.

2-Carboxy-3-methoxy-6-bromophenylacetic Acid (VI) To a solution of the oximino ketone $(\mathrm{V}, 23 \mathrm{~g})$ in $10 \%$ sodium hydroxide $(215 \mathrm{ml})$ was added portionwise

10) Since the acidity of methylene hydrogens of the homophthalic acid (VII) is greater than that of the methyl hydrogens of acetic acid, the intermediate XII seems to be the preferred one. 


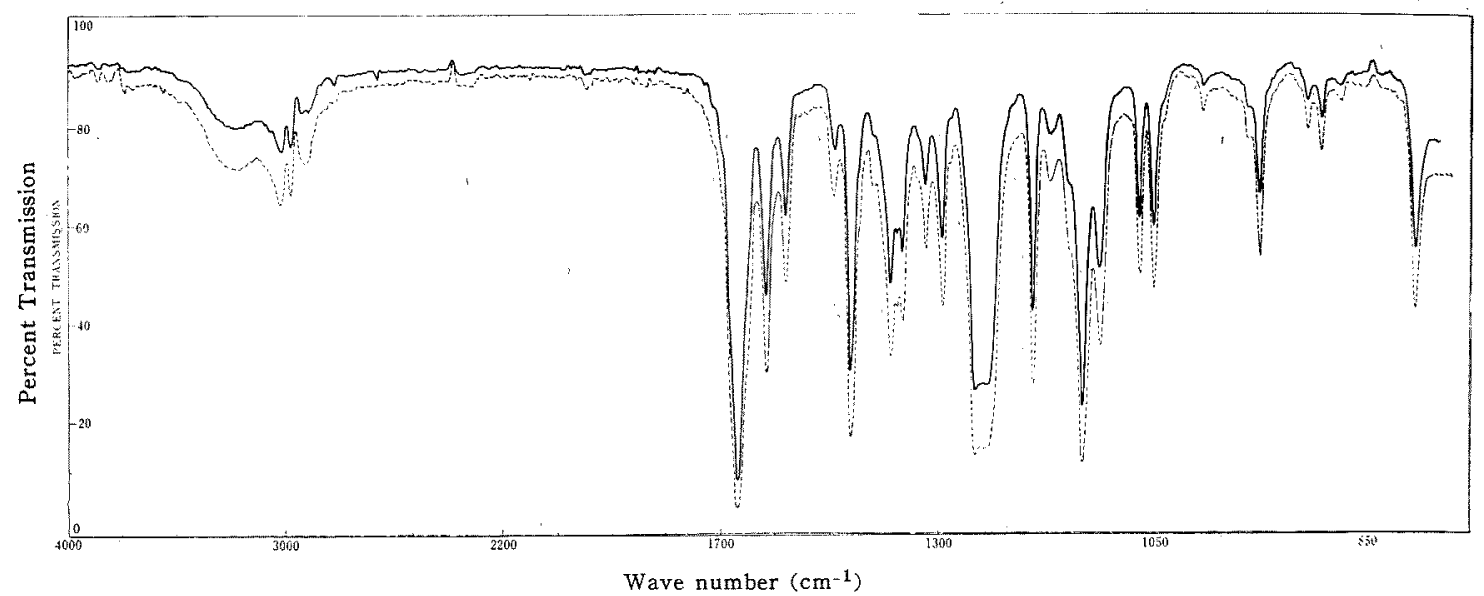

FIG. Infrared of Natural and Racemic Mellein.

Full line: natural mellein (Chloroform solution)
Broken line: acemic mellein

$p$-toluenesulfonyl chloride $(27.3 \mathrm{~g})$ at $35 \sim 40^{\circ} \mathrm{C}$ with stirring. After the addition the mixture was kept at this temperature for $20 \mathrm{~min}$. Then the temperature was raised to $100^{\circ} \mathrm{C}$ and sodium hydroxide $(38 \mathrm{~g})$ was added to the reaction mixture. It was refluxed for 5 hrs., decolorized with charcoal, acidified with concd. hydrochloric acid $(100 \mathrm{ml})$ and extracted with ethyl acetate. The extract was washed with brine, dried and evaporated to give $11.6 \mathrm{~g}(46.9 \%)$ of crystals. Needles from ethyl acetate, m.p. $183.5 \sim 184.5^{\circ} \mathrm{C}$. Anal. Found: $\mathrm{C}, 42.05 ; \mathrm{H}, 3.38$. Calcd. for $\mathrm{C}_{10} \mathrm{H}_{9} \mathrm{O}_{5} \mathrm{Br}$ : C, 41.55; $\mathrm{H}, 3.14 \% . \nu \max .3350,1712,1590 \mathrm{~cm}^{-1}$.

2-Carboxy-3-methoxyphenylacetic Acid (VII) The bromo acid (VI, $10 \mathrm{~g}$ ) in aqueous sodium hydroxide $(5.6 \mathrm{~g}$ in $100 \mathrm{ml})$ was hydrogenated over Raney nickel $\mathrm{W}-7(5 \mathrm{~g})$ at room temperature under atmospheric pressure until the hydrogen uptake ceased. The catalyst was filtered off and the filtrate concentrated and acidified. The precipitated diacid was collected. Further quantities of the product were obtained from the aqueous mother liquor by extraction with ethyl acetate. Yield, $7.1 \mathrm{~g}(97 \%)$. Needles from ethyl acetate, m.p. $165 \sim 166^{\circ} \mathrm{C}$. Anal. Found: C, 57.01; H, 4.91. Calcd. for $\mathrm{C}_{10} \mathrm{H}_{10} \mathrm{O}_{5}: \mathrm{C}, 57.14 ; \mathrm{H}, 4.80 \%$. $\nu_{\max } 1708,1669$, $1595,1583 \mathrm{~cm}^{-1}$

Methyl 2-Carbomethoxy-3-methoxyphenylacetate (VIII) The diacid (VII $8 \mathrm{~g}$ ) in ethyl acetate was esterified with ethereal diazomethane to give $8 \mathrm{~g}(88 \%)$ of oily diester. This was employed for the next step without further purification.
2-Carbomethoxy-3-methoxyphenylecetic Acid (IX) The diester (VIII, 8g) in ethanolic potassium hydroxide ( $3 \mathrm{~g}$ in $90 \mathrm{ml} \mathrm{99 \%} \mathrm{ethanol)} \mathrm{was} \mathrm{refluxed} \mathrm{for} \mathrm{an} \mathrm{hour.}$ After removal of the solvent, the residuc was dissolved in water $(7 \mathrm{ml})$ and acidified $(10 \mathrm{ml}$ cond. hydrochloric acid). The precipitated crystals were collected and the mother liquor was extracted with ethyl acetate. Concentration of the extract gave further amounts of the product. The product was recrystallized from benzene. Yield, $6.0 \mathrm{~g}(80 \%)$. Elongated prisms from benzene, m.p. $106 \sim 107^{\circ} \mathrm{C}$. Anal. Found: C, 59.16; H, 5.33. Calcd. for $\mathrm{C}_{11} \mathrm{H}_{12} \mathrm{O}_{5}: \mathrm{C}, 58.92 ; \mathrm{H}, 5.40 \%$ vmax. $1710,1590 \mathrm{~cm}^{-1}$. A small amount $(0.2 \mathrm{~g})$ of 2 -carboxy-3-methoxyphenylacetic acid was obtained as benzene insoluble fraction.

2-Carbomethoxy-3-methoxy phenlylacetyl chloride (X) A. The half ester (IX, 2g) in purified chloroform $(6 \mathrm{ml})$ was treated with phosphorus trichloride $(3 \mathrm{ml})$. The mixture was kept at room temperature for $18 \mathrm{hrs}$. The upper chloroform layer was concentrated to yield oily product. Remaining phosphorus trichloride in the oil was removed by repeated addition and evaporation of purified chloroform. Yield, about $2 \mathrm{~g}$. This was employed for the next step without further purification. B. The half ester (IX, $0.7 \mathrm{~g}$ ) in chloroform $(4 \mathrm{ml}$ ) was treated with thionyl chloride $(2.2 \mathrm{ml})$ at $40 \sim 48^{\circ} \mathrm{C}$ for 2 hrs. Excess of thionyl chloride and chloroform were removed in vacuo to give an oil $(0.7 \mathrm{~g})$.

3-Methyl-8-methoxyisocoumarin (XI) A. Ethyl ethoxymagnesiomalonate in ether $(10 \mathrm{ml})$ was prepared from ethyl malonate $(1.34 \mathrm{~g})$, magnesium $(0.22 \mathrm{~g})$ and 
ethanol $(1.6 \mathrm{ml})$. Ethanol was removed from the mixture by codistillation with dry benzene. The residure was dissolved in dry ether $(10 \mathrm{ml})$. To this solution was added the oily acyl chloride $(X, 2 \mathrm{~g})$ in ether $(10 \mathrm{ml})$. The mixture was refluxed for $30 \mathrm{~min}$., cooled and treated with dilute sulfuric acid $(1: 10 ; 22 \mathrm{ml})$. The ethereal layer was separated, washed with water, dried and concentrated to give an oil, $\nu_{\max } .1732,1582 \mathrm{~cm}^{-1}$ This was dissolved in acetic acid $(7 \mathrm{ml})$. To this was added concd. hydrochloric acid $(5.8 \mathrm{ml})$ and the mixture refluxed for $6 \mathrm{hrs}$. After cooling, the mixture was diluted with water and extracted with ethyl acetate. The extract was washed with water, dried and concentrated to give $1.5 \mathrm{~g}$ ( $88.3 \%$ from the half ester IX) of oil. $\nu \max .1720,1656,1593,1564 \mathrm{~cm}^{-1}$ B. 2Carboxy-3-methoxyphenylacetic acid (VII, 4.0g) in acetic anhydride $(100 \mathrm{ml})$ was refluxed for $9 \mathrm{hrs}$. The solvent was removed in vacuo. The residue was dissolved in acetic anhydride $(20 \mathrm{ml})$ containing sodium acetate $(6.5 \mathrm{~g})$. The mixture was heated under reflux for 11 hrs. Then water $(36 \mathrm{ml})$ was added while warm and the resulting dark solution decolrized with charcoal. The solution was diluted with water and extracted with ether $(100 \mathrm{ml} \times 4)$. Removal of the solvent gave $2.2 \mathrm{~g}$ of crystals. The product was purified by sublimation (bath temp.: $120 \sim 130^{\circ} \mathrm{C}$, pressure: $8 \mathrm{mmHg}$ ) followed by recrystallization from ethanol. Prisms, m.p. $109.5 \sim 110.5^{\circ} \mathrm{C}$. Anal. Found: C, 69.92; H, 5.60. Calcd. for $\mathrm{C}_{11} \mathrm{H}_{10} \mathrm{O}_{3}: \mathrm{C}, 69.46 ; \mathrm{H}, 5.30 \%$. $\nu$ max. 1723, $1661,1595,1565 \mathrm{~cm}^{-1} . \lambda_{\max }(\mathrm{EtOH}) \mathrm{m} \mu(\log \varepsilon) 236$

\section{$(4.43), 255(4.16) 336(3.85)$}

3-Methyl-8-hydroxyisocoumarin (III) Crude oily 3-methyl-8-methoxy-isocoumarin (XI, 1.5g) obtained by the above described procedure $A$ was heated under reflux for 6 hrs. with acetic acid $(22 \mathrm{ml})$ and hydriodic acid (d $1.7 ; 5.2 \mathrm{ml})$. The mixture was concentrated in vacuo, diluted with water $(100 \mathrm{ml})$ and extracted with ethyl acetate. The organic layer was separated, washed with water, aqueous sodium thiosulfate and saturated brine. The dried extract was concentrated in vacuo to give $0.8 \mathrm{~g}(58 \%)$ of crystals. Needles from methanol, m.p. $101 \sim 102^{\circ} \mathrm{C}$. Anal. Found: C, 68.51 ; $\mathrm{H}, 4.69$. Calcd. for $\mathrm{C}_{10} \mathrm{H}_{8} \mathrm{O}_{3}: \mathrm{C}, 68.18 ; \mathrm{H}, 4.58 \%$. $\nu_{\max } 3070,1680,1644,1610,1568 \mathrm{~cm}^{-1}$. $\lambda_{\max }$. $(\mathrm{EtOH}) \mathrm{m} \mu(\log \varepsilon) 219(4.45), 227(4.50), 233(4.47)$, $253.5(4.21), 271(3.98), 331(3.88)$. Infrared and ultraviolet spectra were identical with the published data. ${ }^{7)}$ The crystalline isocoumarin (XI, $500 \mathrm{mg}$ ) obtained by the procedure $\mathrm{B}$ was demethylated as above to give $300 \mathrm{mg}$ of crystals, identical in every respect with the above characterized substance.

(士)-Mellein (I). 3-Methyl-8-hydroxyisocoumarin (III) was hydrolyzed with alkali, reduced with sodium borohydride and lactonized by acid to give ( \pm -mellein as described by Bendz. ${ }^{7}$ Elongated prisms, m.p. 37 $38^{\circ} \mathrm{C}$. Anal. Found: C, 67.39; H, 5.70. Cacd. for $\mathrm{C}_{10} \mathrm{H}_{10} \mathrm{O}_{3}: \mathrm{C}, 67.40 ; \mathrm{H}, 5.66 \%$. Infrared spectrum was recorded in the text. $\nu_{\max }$ (Nujol) $3120,3060,1662$, $1618,1580,810 \mathrm{~cm}^{-1}\left(\mathrm{CHCl}_{3}\right) .3200,1674,1620,1582$, $810 \mathrm{~cm}^{-1}$. 